\title{
Refuse attracts? Effect of refuse dumps of leaf-cutting ants on floral traits
}

\author{
ANAHÍ FERNANDEZ, * (D) MARIANA TADEY (D) AND ALEJANDRO G. FARJI-BRENER (D) \\ Laboratorio Ecotono, Inibioma-Conicet, Pasaje Gutiérrez 1125, Bariloche 8400, Argentina (Email: \\ anahi.r.fernandez@gmail.com)
}

\begin{abstract}
The nutrient-rich organic waste generated by ants may affect plant reproductive success directly by enhancing fruit production but also indirectly, by affecting floral traits related with pollinator attraction. Understanding how these soil-nutrient hot spots influence floral phenotype is relevant to plant-pollination interactions. We experimentally evaluated whether the addition of organic waste from refuse dumps of the leaf-cutting ant Acromyrmex lobicornis (Hymenoptera: Formicidae: Attini) alters floral traits associated with pollinator attraction in Eschscholzia californica (Ranunculales: Papaveraceae), an entomophilous herb. We analysed flower shape and size using geometric morphometric techniques in plants with and without the addition of refuse-dumps soil, under greenhouse conditions. We also measured the duration of flowering season, days with new flowers, flower production and floral display size. Plants growing in refuse-dumps soil showed higher flower shape diversity than those in control soil. Moreover, plants in refuse-dumps soil showed bigger flower and floral display size, longer flowering season, higher number of flowering days and flower production. As all these variables may potentially increase pollinator visits, plants in refuse-dumps soil might increase their fitness through enhanced attraction. Our work describes how organic waste from ant nests may enhance floral traits involved in floral attraction, illustrating a novel way of how ants may indirectly benefit plants.
\end{abstract}

Key words: Acromyrmex lobicornis, floral traits, geometric morphometric, leaf-cutting ants, soil nutrients.

\section{INTRODUCTION}

Floral traits are fundamental for ensuring reproductive success in plants that rely on biotic pollination. Pollinators can associate floral colour, size and/or shape with nutritional rewards like nectar, pollen or oils (Tadey 2012; Schiestl \& Johnson 2013). For example, greater corolla sizes enhance visual attraction and, therefore, pollinator visitation frequency in several plant species (Grindeland et al. 2005; Gómez et al. 2008a). On the other hand, floral morphology may also facilitate the landing and contact between reproductive parts of the plants and floral visitors (Nilsson 1988; Tadey \& Aizen 2001). Accordingly, changes in corolla shape among related species and, even, within the same plant species often attract different kinds of pollinators (Gómez et al. 2008b). As the expression of most of floral traits depends on nutritional plant level (Gardener \& Gillman 2001), understanding how changes in the surrounding environmental conditions influence floral phenotype is particular relevant to plant-pollination interactions.

Soil nutrients may affect floral traits directly increasing the number of flowers, but also indirectly influencing the interactions of plants with their pollinators (Campbell \& Halama 1993). For example,

${ }^{\star}$ Corresponding author.

Accepted for publication July 2018.

C 2018 Ecological Society of Australia fertilized plants of Ipomopsis aggregata produced flowers with wider corolla, more nectar and longer periods of blooming than non-fertilized plants, receiving more floral visitors (Burkle \& Irwin 2009). Similarly, plants of Chuquiraga oppositifolia under nitrogenenrichment treatments produced more flowers per individual than control plants, enhancing pollinator visitation frequency (Muñoz et al. 2005). However, these works used artificial fertilizers instead of natural nutrient sources, such as nutrient-enriched soil as a consequence of the accumulation and decomposition of organic matter (Peinemann 1998; Voroney \& Heck 2007). Experiments using natural organic matter are thus more realistic than the addition of commercial fertilizers (Tibbett 2000). Despite this, few studies use naturally enriched substrates to study the effect of nutrient addition on floral traits. For example, plants of Cucumis sativus growing on soils enriched with vermicomposting had heavier flowers and pollen with higher protein content than control plants, receiving more and longer pollinators visits per flower (Cardoza et al. 2012). In sum, more studies using natural nutrient sources are needed to understand what really happens in nature and how we can improve floral attraction in agricultural fields.

One of the major natural sources of soil nutrients in the Neotropics is the organic waste produced by leaf-cutting ants (Farji-Brener \& Werenkraut 2015). 
These ants collect vegetable material to feed a symbiotic fungus, which is the main food source for their larvae (Hölldobler \& Wilson 1990). The vegetable material not processed by the fungus is accumulated in internal specific chambers or in external piles on the soil surface (Farji-Brener et al. 2016). Several studies have shown that this organic waste (hereafter, refuse dump) have more nutrients than adjacent soils (reviewed in Farji-Brener \& Werenkraut 2015), which is accessible to neighbouring plants (da S L Sternberg et al. 2007; Farji-Brener \& Ghermandi 2008). Consequently, plants growing on, or near external refuse dumps, and those that reach internal refuse chambers through their root system often show higher growth, biomass and reproduction rate than those plants growing on adjacent, control soils (FarjiBrener \& Werenkraut 2015).

The enhanced fitness in plants associated with refuse-dump soil can be a direct consequence of a higher assignation of nutrients to flower and fruit production (Farji-Brener \& Ghermandi 2008). However, increased plant fitness may also be an indirect consequence of changes in floral traits involved in floral attraction, enhancing pollinator visitation rate. Here, we hypothesize that a natural nutrient source affects the attractiveness of floral traits. To test this, we experimentally added refuse-dump soil of the leaf-cutting ant, Acromyrmex lobicomis Emery (Hymenoptera: Formicidae: Attini), on plants of Eschscholzia californica Cham. (Ranunculales: Papaveraceae), an insect pollinated herb. We have focused our study in floral traits that are associated with pollinators attraction and that can be potentially affected by nutrient addition (Campbell \& Halama 1993; Muñoz et al. 2005; Cardoza et al. 2012), particularly in flower shape, a less studied floral trait that play a key role in pollination (Gómez et al. 2008b). Previous studies found that leaf shape varies in response to the addition of fertilizers (Njoku 1957; Gosler et al. 1994). Given that petals (and sepals) are modified leaves (Coen \& Meyerowitz 1991), increasing nutrient content may affect flower shape. Specifically, we predict that plants growing in refuse-dump soil will produce bigger flowers with different shapes, than the plants growing on control soil. At plant level, we also expect that the access to a nutrient-rich substrate produces plants with more extended flowering season, increases flower production and enlarges floral display, all enhancing visual traits that potentially attract flower visitors.

\section{METHODS}

\section{Study species}

Eschscholzia californica, California poppy, is an annual herb native to North America that is well adapted to disturbed areas of Patagonian steppes (Correa 1984). In the study area, it is commonly found growing near or even in the refuse dumps of leaf-cutting ants (personal observation, Appendix S1). This species is partially self-compatible but depends on biotic pollination. Honeybees, bumblebees and some solitary hymenopterans are its main pollinators (Cook 1962). We consider this herb to be a good model to test our hypothesis because it is well adapted to poor soils like those where A. lobicornis colonies are found (Kirkpatrick 1998). In addition, unlike most Patagonian herbs, E. californica has fast growth and large flowers, which enable us to grow it in greenhouse conditions and manipulate the flowers to apply geometric morphometric techniques (Fig. 1a).

Acromyrmex lobicornis is the only leaf-cutting ant inhabiting Patagonia and is frequent to find it in disturbed roadside areas of Patagonian steppe (Farji-Brener \& Ruggiero 1994). It constructs dome-shaped nest mounds (1 m high and wide) made of dry twigs and soil. Nearby the dome, the ants place a few flat piles of refuse dumps (hereafter RD), accessible to neighbouring plants (Farii-Brener \& Ghermandi 2000). These RD have a higher content of organic matter and nutrients; water retention capacity and microbial activity than adjacent soils (Table 1) (Tadey \& Farji-Brener 2007; Fernandez et al. 2014).

\section{Greenhouse experiment}

During April of 2015, we sowed seeds of E. californica under two substrate treatments: control soils (C) and ant refuse-dump soil (RD). We collected both substrates from a steppe region near S. C. Bariloche city $\left(40^{\circ} 53^{\prime} 40^{\prime \prime} \mathrm{S} 71^{\circ}\right.$ $\left.02^{\prime} 12^{\prime \prime} \mathrm{W}\right)$. We randomly selected 10 nests of $A$. lobicornis and collected samples of their refuse-dump and control soils that were at least $2 \mathrm{~m}$ away from each ant nests. Levels of nutrient enrichment of the refuse-dump samples showed relatively low levels of variation among them (Table 1). Therefore, we pooled all the refuse-dump soil samples in a single composed sample and compared it with a composed sample from control areas. Then, we used those composed samples to sow the seeds of E. californica. A total of 74 seeds (one per pot, 37 per treatment) were sown in pots of $1.6 \mathrm{~L}$ and regularly watered.

\section{Floral traits}

In the greenhouse, 7 months after sowing, we measured the floral traits. In each plant, at flower level we measured flower shape and size using geometric morphometric methods. We took pictures of all the flowers under standardized conditions to avoid scale and co-planarity errors at moment of digitalization (Zelditch et al. 2004). We cut the flowers, flattened and adhered them to a white cardboard sheet located horizontally at $50 \mathrm{~cm}$ below a digital camera on a tripod. This technique is very useful to perform flower measurements, however, is partially destructive (i.e. flowers are cut from the plant), which together with the fact that plants were growing in a greenhouse, prevented us to estimate pollinator visitation frequency. On the other hand, at plant level, we registered: duration of flowering season 


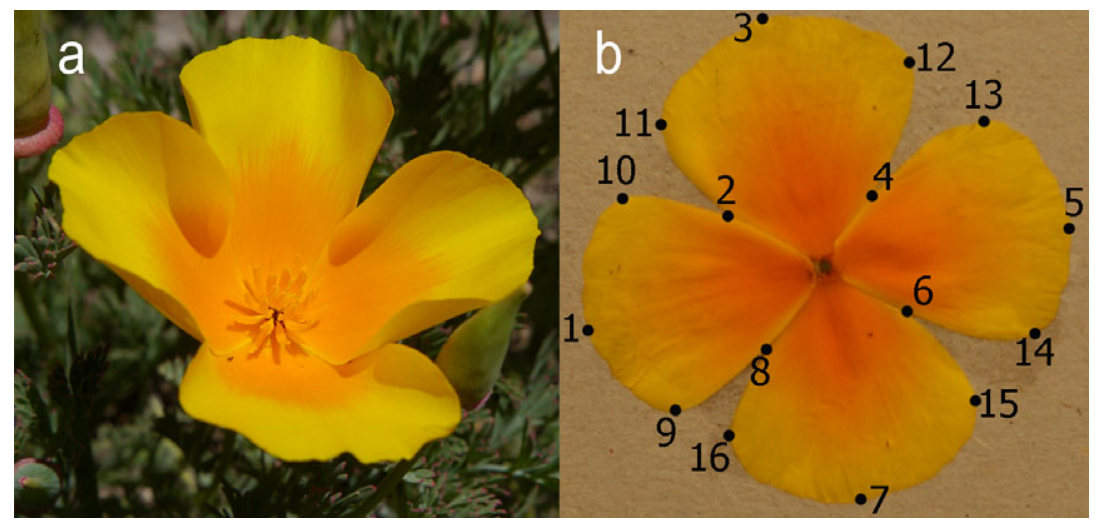

Fig. 1. Flower shape of Eschscholzia californica: (a) flower in nature; (b) planar picture of the flower with schematic representation of the 16 landmarks (LMs) (black dots) used in this study. The LMs were depicting the following criteria: LMs 1 and 5 are the points of maximum curvature at the middle of superior petals, whereas LMs 3 and 7 are for the inferior petals; LMs $9,10,11,12,13,15$ and 16 are the points of maximum curvature on petal sides; LMs $2,4,6$ and 8 are the intersection points between adjacent petals.

Table 1. Mean nutrients concentration $( \pm \mathrm{SE})$ for control $(\mathrm{C})$ and refuse dumps from Acromyrmex lobicornis nest (RD) substrates. $F$ and $P$ values correspond to MANOva, univariate results

\begin{tabular}{llrrr}
\hline & \multicolumn{1}{c}{ C } & \multicolumn{1}{c}{ RD } & $F$ & $P$ \\
\hline $\mathrm{C}(\%)$ & $0.34 \pm 0.03$ & $21.56 \pm 2.14$ & 98.4 & $<0.001$ \\
$\mathrm{~N}(\%)$ & $0.03 \pm 0.00$ & $2.4 \pm 0.42$ & 31.8 & $<0.001$ \\
$\mathrm{P}\left(\mu \mathrm{g} \mathrm{g}^{-1}\right.$ substrate) & $6.22 \pm 1.1$ & $223.5 \pm 29.1$ & 55.7 & $<0.001$ \\
$\mathrm{~K}\left(\mathrm{~g} \mathrm{~kg}^{-1}\right.$ substrate) & $0.17 \pm 0.01$ & $4.9 \pm 0.47$ & 103.5 & $<0.001$ \\
\hline
\end{tabular}

(numbers of days between the first and last day with flowers), days with new open flowers, total flower production and size of floral display (i.e. number of open flower per day). Once, flowering season was over, we weighed vegetative biomass of all individuals.

\section{Data analysis}

The methodology of geometric morphometry allows the statistical analysis of the shape of biological structures independently of their orientation, position or size, through a superimposition method (Rohlf \& Marcus 1993). This methodology represents the shape of these structures through the configuration of Cartesian landmarks coordinates in two- or three-dimensional spaces (Mitteroecker \& Gunz 2009). We defined a configuration of 16 landmarks (LM) to represent the flower shape of E. californica (Fig. 1b). To plot the LMs on our specimens (i.e. flowers) we used the free software tpsDigver 2. All LMs were plotted by the same person to minimize potential biases of visual perception. We used 'centroid size' (CS) as estimator of size, defined as the square root of the summed squared distances of each landmark from the centre of the flower (Mitteroecker \& Gunz 2009). For morphometric analysis, we used free software MorphoJ $1.06 \mathrm{~d}$ (Klingenberg 2011). To detect a possible allometry effect (i.e. shape variations owing to size variations), we fitted a multivariate regression model (i.e. shape vs. size) (Monteiro 1999). For further analysis, we used regression residuals to avoid allometry effect
(Klingenberg \& Marugán-Lobón 2013). We used a Principal Components Analysis (PCA) to describe patterns of shape dispersion in both treatments (Klingenberg 2011) and discriminant analysis to detect statistical differences between them (Campbell \& Atchley 1981).

To compare the effect of refuse-dump soil on flower size (CS), total production of flowers, length of flowering season and number of days with new flowers, we performed a multivariate analysis of variance (MANOVA) with substrate type as a fixed factor. We tested normality by a ShapiroWilk test and variance homogeneity by a Levene's test. Data were log transformed when necessary. To analyse the effect of both substrates on display size along flowering season, we used a repeated measures analysis of variance (ANOVA), using the mean display size per week calculated from the second week of October to the first week of April.

\section{RESULTS}

Flowering season started in October 2015 and ended in April 2016, 100\% of RD and 85\% of C individuals produced at least one flower along the flowering season.

\section{Floral traits at flower level}

We obtained 75 digital pictures of flowers from 32 plants growing on $\mathrm{RD}$ and 51 flowers of 27 plants 
growing on $\mathrm{C}$ treatments, to analyse their size and shape with geometric morphometric techniques. Flowers of RD plants were larger $\left(F_{(1,52)}=5\right.$, $P=0.02$, Fig. 3a) than C flowers, however, only $12.3 \%$ of the total shape variation was due to the size (i.e. allometry effect $(P<0.001))$. When analysing the residuals with a PCA, the first two axes explained $70 \%$ of the total variance $(59 \%$ and $11 \%$ respectively). Along axis 1 , flower shape was associated with the variation in the position of LMs depicting petals intersections (i.e. $\mathrm{LMs}=2,4,6$ and 8; Fig. 2a). Towards the left of Axis 1, LMs 2, 4, 6 and 8 were near the centroid of the shape while towards the right, LMs were closer to flower perimeter (Fig. 2a). Along Axis 2, the shape varied inconsistently without a clear pattern (Fig. 2a). In addition, neither of both substrate treatments affected the floral symmetry (Appendix S1). In addition, the shape of the flowers produced by $\mathrm{RD}$ plants showed higher dispersion than those in $\mathrm{C}$ plants (Fig. 2a). Despite some overlapping, flowers from $\mathrm{RD}$ plants showed different shapes than flowers from C plants $\left(T^{2}=60.4, P=0.03\right.$, Fig. $\left.2 b\right)$. Furthermore, some of the shapes were only found in one substrate type (Fig. 2b). Overall, flowers from C plants showed LMs of petal intersection more closer to the centroid than those from RD (Fig. 2b).

\section{Floral traits at plant level}

Refuse-dump soil affected all floral traits measured at plant level (MANOVA, Wilk's $\lambda=0.51, F_{(4,49)}=$ 12.3, $P<0.001)$. RD plants showed greater floral display (i.e. number of open flower per day; $F_{(1,70)}$ =53.9, $P<0.001$, Fig. 4), longer flowering season $\left(F_{(1,52)}=8.2, P=0.05\right.$, Fig. $\left.3 b\right)$, greater number of days with new flowers $\left(F_{(1,52)}=40.7, P<0.001\right.$, Fig. 3c) and higher flower production than $C$ plants $\left(F_{(1,52)}=43.1, P<0.001\right.$, Fig. $\left.3 d\right)$. The higher floral display of $\mathrm{RD}$ plants was observed in four intervals of flowering season $\left(F_{\text {week }}(24,70)=16.5\right.$, $P<0.001$, Fig. 4). There was also an interaction between the substrate and the interval of flowering season (i.e. week) $\left(F_{(24,70)}=12.3, P<0.001\right.$, Fig. 3), RD plants showed four prominent flowering peaks, whereas the floral display by $\mathrm{C}$ plants was similar during all the flowering season (Fig. 4). In addition, vegetative biomass for individual growing on $\mathrm{RD}$ was higher than $\mathrm{C}$ plants $\left(t_{(35)}=8.9, P<0.001\right)$ (Appendix S1).

\section{DISCUSSION}

Our work describes how organic waste from ant nests change floral traits associated with pollinators attraction, illustrating an indirect novel effect of ants on plants (Campbell \& Halama 1993; Gardener \& Gillman 2001). Specifically, we experimentally demonstrated that the addition of $A$. lobicornis refuse dumps (RD), a nutrient-rich substrate, greatly affects the floral traits of $E$. californica both at flower and plant level. At flower level, plants growing in RD showed higher variation in shape and produced 1.1fold larger flowers than control plants. At plant level, individuals growing in RD substrate showed 1.5-fold longer flowering season length, 3.4 higher flower production and up to 7.4 larger floral display size than plants growing in control soils. All these traits affect pollinator assemblage composition and their foraging behaviour, with potential consequences on plant reproduction.

Plants attractiveness may occur at flower level by changes in shape, size, scent, colour and/or rewards (Galen \& Newport 1988; Rosas-Guerrero et al. 2014). The addition of nutrients may allow the plant to allocate more resources for improving flower attraction (Muñoz et al. 2005; Burkle \& Irwin 2009). We found that the addition of $\mathrm{RD}$ significantly varied flower shape and increased its size. Previous works have observed that bigger flowers are preferred by both of the mainly pollinators of E. californica, Apis mellifera and Bombus sp. (Johnson et al. 1995; Martin 2004). Moreover, flower size is positively associated with rewards availability, explaining the increased pollinator visitation frequency to larger flowers (Campbell et al. 1991; Gómez et al. 2008a). Although less studied, flower shape is also an important trait for pollinator attraction because it may affect the detection capacity (i.e. visual cue) and efficiency (i.e. increasing contact) of different floral visitors. Hymenopterans can detect intraspecific variations in floral shape, and their preference over it varies among different functional groups (Gómez et al. 2008b). Interestingly, we found that the addition of RD produced greater variation in flower shape, potentially enhancing the range of different floral visitors respect to $\mathrm{C}$ plants. In general, $\mathrm{RD}$ shapes have larger petal area with smaller gaps between them, leading to a more spherical flower shape than control ones, whose shapes were more star like (Fig. 2b). This more spherical shape could be more visible for pollinators at long distance than star-like shape. Overall, the change in flower shape and size found in this work may affect the identity and visitation frequency of pollinators (Gómez et al. 2008b).

Floral attractiveness is also influenced by floral traits at plant level. A higher flower production along an extended flowering season may enhance pollination effectiveness through the visitation of a wider range of pollinator abundance and richness (Appendix S1) (Herrera 1988; Fishbein \& Venable 1996; Bosch et al. 1997). In addition, a larger number 
a

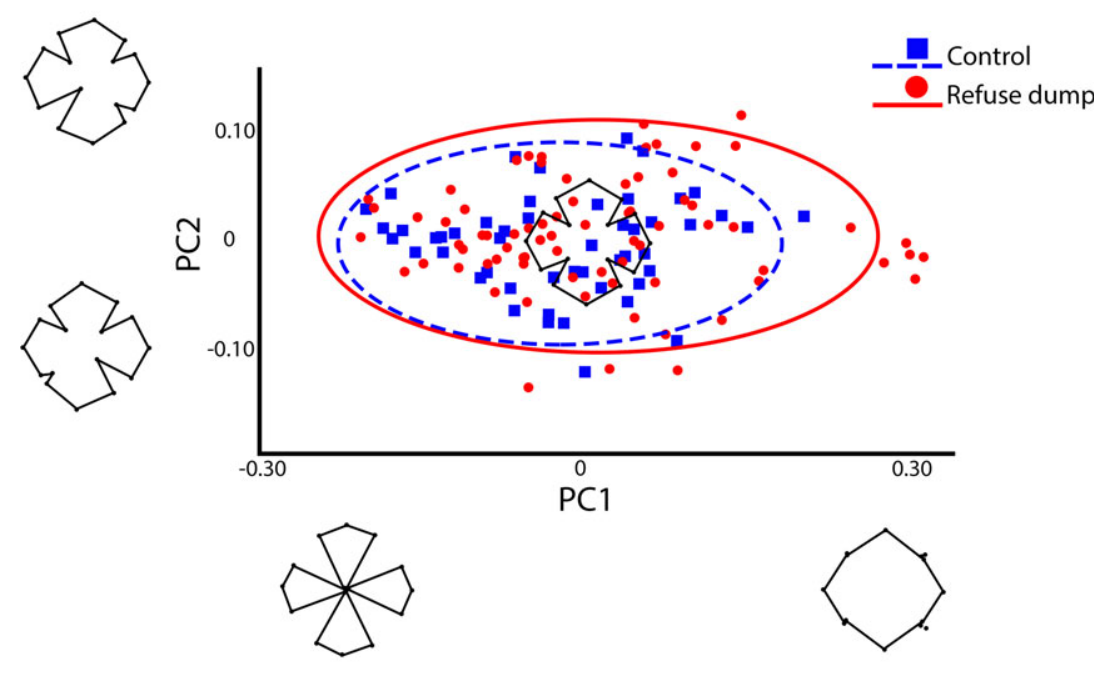

b

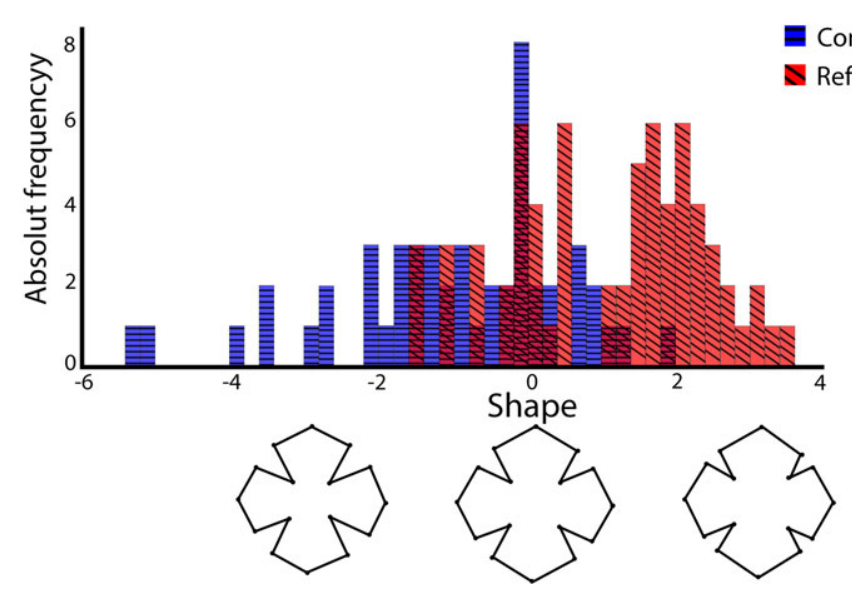

Fig. 2. (a) Scatterplot of the two-first Principal Components that explained $70 \%$ the total variance of floral shape (59\% and $11 \%$ respectively). Floral schemes in the centre of points cloud represent the mean flower shape (i.e. consensus flower) and schemes at the end of the axes (PC1 and PC2) represent the extreme variations in flower shape along them. Circle points represent flowers from plants that grew on refuse dump and square points were from plants growing on control soil. Ellipses depict the $95 \%$ confidence intervals, dotted line corresponds to $\mathrm{C}$ treatment and continous line to RD treatment. (b) Histograms showing the absolute frequency of different shapes produced by individuals of Eschscholzia califormica growing under two substrate treatments; control soil (C, bars with horizontal lines) and refuse dump from Acromyrmex lobicornis nest (RD, bars with diagonal lines). Below horizontal axis, the central floral scheme represents the mean shape (i.e. consensus flower), whereas the scheme at left represents the shapes that are found only in Control plants and at right those only found in RD plants. Both treatments (RD vs. C) showed a significantly different flower shape.

of flowers per plant may increment flower fecundity and seed production through increased visitation frequency (Ohara \& Higashi 1994). From a pollinator perspective, an extended blooming may lead to better opportunities of reward availability, both in quantity and quality, considering that bees and bumblebees are able to learn the locations of good resources (Chittka et al. 1999). In this way, plants with more open flowers usually receive more pollinator's visits (Grindeland et al. 2005). On the other hand, hymenopterans are usually more attracted to bigger floral display because of its conspicuousness and visual impact. Moreover, bigger floral display offers higher amount of rewards than smaller floral display reducing foraging costs (Eckhart 1991; Ohara \& Higashi 1994). Although we were not able to register pollinator visitation frequency in our sampling plants because of experimental limitations, as they were growing in greenhouse conditions, it is known that the floral traits discussed above enhance pollinator 
a

\section{Flower size}

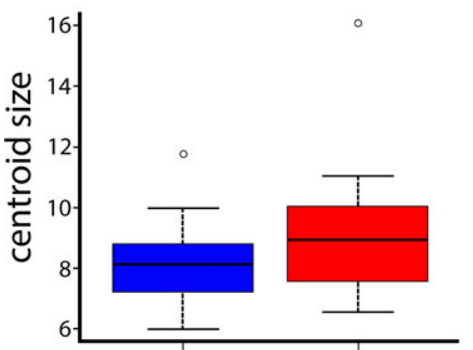

C

Days with new open flowers

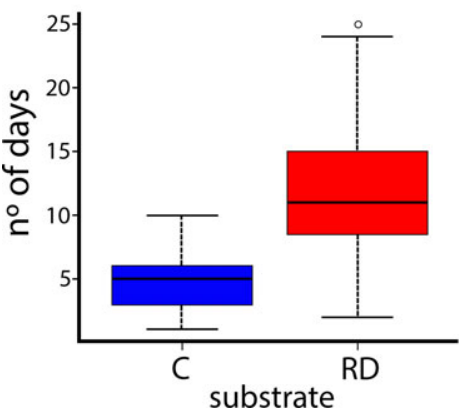

b

Duration of flowering season

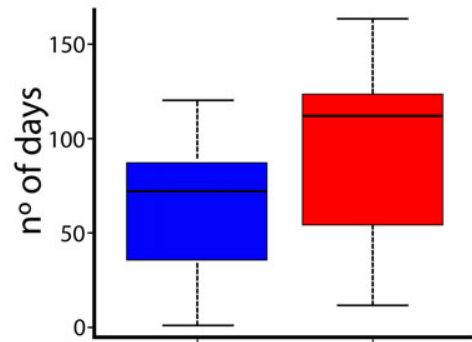

d

Fig. 3. Effect of substrate treatments, controls soil $(\mathrm{C})$ and refuse dump (RD) on the median and interquartile ranges (empty circles are outliers) of the following response variables measured in Eschscholzia californica: (a) flower size estimated as centroid size (CS), defined as the square root of the summed squared distances of landmarks from the centre of the form; (b) duration of flowering season (number of days between the first and last day with new flowers); (c) days with new flower; (d) total number of flower produced along flowering season.

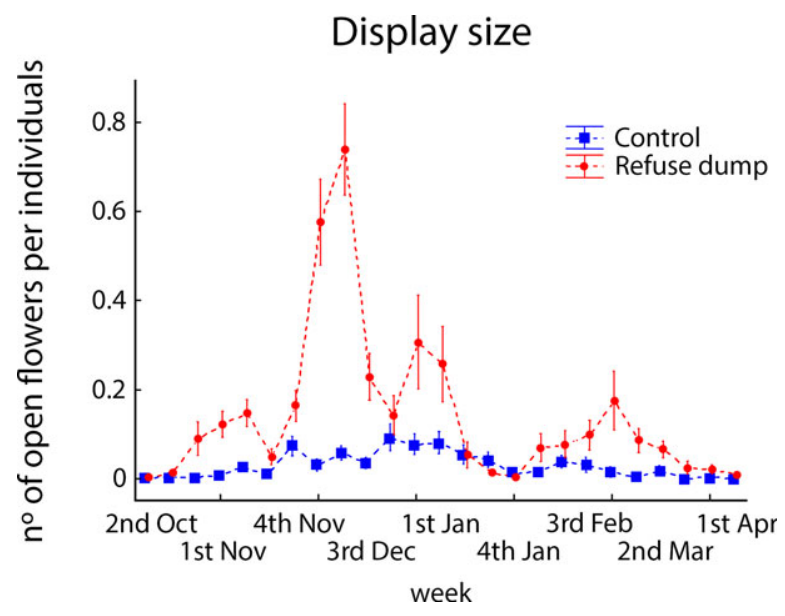

Fig. 4. Mean display size \pm SE for both substrates treatments, control soil (C, square points) and refuse dump from Acromyrmex lobicornis nest (RD, circle points). Display size is defined as the number of open flower per individual of Eschscholzia californica in the same day, and was measured along the flowering season from the 2nd week of October to the 1 st week of April (spring to autumn). attraction and reproductive success of plants (Herrera 1993; Grindeland et al. 2005). Future field experiments should confirm whether these changes in floral traits effectively affect pollinator visitation frequency and plant fitness in E. californica.

In natural conditions, plants growing on, or near, ant nests often show a higher reproductive success than plants growing far from them (Farji-Brener \& Werenkraut 2017). The most common explanation of this pattern is that plants are able to allocate the nutrients obtained from refuse-dump soil to increase the production of flowers and fruits (Farji-Brener \& Ghermandi 2008). Our results suggest another indirect way by which ants, through the production of nutrient-rich organic waste, may benefit plants: promoting changes in floral traits associated with pollinator attraction. Therefore, plants accessing ant organic waste not only can increase their flower and fruit production but also show flowers more attractive to pollinators. The relative importance of these two complementary effects deserves further studies. Overall, our results may have conceptual and applied implications. First, they illustrate how indirect effects 
may act in nature, emphasizing that an ecological pattern may be consequence of several complementary processes. Secondly, the use of refuse-dump soil as a natural fertilizer can be useful in restorations practices that need to enhance pollinator services, especially in poor soil ecosystems.

\section{ACKNOWLEDGEMENTS}

Authors thank to Florencia Baudino, Santiago Aisen and Patricia Suarez for their collaboration in greenhouse tasks.

\section{REFERENCES}

Bosch J., Retana J. \& Cerdá X. (1997) Flowering phenology, floral traits and pollinator composition in a herbaceous Mediterranean plant community. Oecologia 109(4), 58391.

Burkle L. A. \& Irwin R. E. (2009) The effects of nutrient addition on floral characters and pollination in two subalpine plants, Ipomopsis aggregata and Linum lewisii. Plant Ecol. 203(1), 83-98.

Campbell N. A. \& Atchley W. R. (1981) The geometry of canonical variate analysis. Syst. Biol. 30(3), 268-80.

Campbell D. R. \& Halama K. J. (1993) Resource and pollen limitations to lifetime seed production in a natural plant population. Ecology 74(4), 1043-51.

Campbell D. R., Waser N. M., Price M. V., Lynch E. A. \& Mitchell R. J. (1991) Components of phenotypic selection: pollen export and flower corolla width in Ipomopsis aggregata. Evolution 45(6), 1458-67.

Cardoza Y. J., Harris G. K. \& Grozinger C. M. (2012) Effects of soil quality enhancement on pollinator-plant interactions. Psyche 2012, 1-8.

Chittka L., Thomson J. D. \& Waser N. M. (1999) Flower constancy, insect psychology, and plant evolution. Naturwissenschaften 86(8), 361-77.

Coen E. S. \& Meyerowitz E. M. (1991) The war of the whorls: genetic interactions controlling flower development. Nature 353(6339), 31.

Cook S. A. (1962) Genetic system, variation, and adaptation in Eschscholzia californica. Evolution 16(3), 278-99.

Correa M. N. (1984) Dicotiledoneas daliapetales (Salicacea a Cruciferae). In: Flora Patagónica(ed M. N. Correa). INTA, Buenos Aires.

Eckhart V. M. (1991) The effects of floral display on pollinator visitation vary among populations of Phacelia linearis (Hydrophyllaceae). Evol. Ecol. 5(4), 370-84.

Farji-Brener A. G. \& Ghermandi L. (2000) The influence of nests of leaf-cutting ants on plant species diversity in road verges of northern Patagonia. F. Veg. Sci. 11, 453-60.

Farii-Brener A. G. \& Ghermandi L. (2008) Leaf-cutting ant nests near roads increase fitness of exotic plant species in natural protected areas. Proc. R. Soc. B. 275, 143140.

Farji-Brener A. G. \& Ruggiero A. (1994) Leaf-cutting ants (Atta and Acromyrmex) inhabiting Argentina: patterns in species richness and geographical range sizes. F. Biogeogr. $21,391-9$.
Farji-Brener A. G. \& Werenkraut V. (2015) A meta-analysis of leaf-cutting ant nest effects on soil fertility and plant performance. Ecol. Entomol. 40(2), 150-8.

Farji-Brener A. G. \& Werenkraut V. (2017) The effects of ant nests on soil fertility and plant performance: a metaanalysis. F. Anim. Ecol. 86(4), 866-77.

Farji-Brener A. G., Elizalde L., Fernández-Marín H. \& Amador-Vargas S. (2016) Social life and sanitary risks: evolutionary and current ecological conditions determine waste management in leaf-cutting ants. Proc. R. Soc. B. 283(1831), 1-7.

Fernandez A., Farii-Brener A. G. \& Satti P. (2014) Moisture enhances the positive effect of leaf-cutting ant refuse dumps on soil biota activity. Austral Ecol. 39(2), 198-203.

Fishbein M. \& Venable D. L. (1996) Diversity and temporal change in the effective pollinators of Asclepias tuberosa. Ecology 77(4), 1061-73.

Galen C. \& Newport M. E. A. (1988) Pollination quality, seed set, and flower traits in Polemonium viscosum: complementary effects of variation in flower scent and size. Am. F. Bot. 75, 900-5.

Gardener M. C. \& Gillman M. P. (2001) The effects of soil fertilizer on amino acids in the floral nectar of corncockle, Agrostemma githago (Caryophyllaceae). Oikos 92, 101-6.

Gómez J. M., Bosch J., Perfectti F., Fernández J. D., Abdelaziz M. \& Camacho J. P. M. (2008a) Association between floral traits and rewards in Erysimum mediohispanicum (Brassicaceae). Ann. Bot. 101(9), 1413-20.

Gómez J. M., Bosch J., Perfectti F., Fernández J. D., Abdelaziz M. \& Camacho J. P. M. (2008b) Spatial variation in selection on corolla shape in a generalist plant is promoted by the preference patterns of its local pollinators. Proc. $R$. Soc. B. 275(1648), 2241-9.

Gosler A. G., Kelly C. K. \& Blakey J. K. (1994) Phenotypic plasticity in leaf morphology of Crataegus monogyna (Rosaceae): an experimental study with taxonomic implications. Bot. F. Linn. Soc. 115(3), 211-9.

Grindeland J. M., Sletvold N. \& Ims R. A. (2005) Effects of floral display size and plant density on pollinator visitation rate in a natural population of Digitalis purpurea. Funct. Ecol. 19(3), 383-90

Herrera C. M. (1988) Variation in mutualisms: the spatiotemporal mosaic of a pollinator assemblage. Biol. $\mathcal{F}$. Lin. Soc. 35(2), 95-125.

Herrera C. M. (1993) Selection on floral morphology and environmental determinants of fecundity in a hawk mothpollinated violet. Ecol. Monogr. 63(3), 251-75.

Hölldobler B. \& Wilson E. O. (1990). The Ants. Belknap, Harvard University Press, Cambridge. Science, 248 (4957), $897-8$.

Johnson S. G., Delph L. F. \& Elderkin C. L. (1995) The effect of petal-size manipulation on pollen removal, seed set, and insect-visitor behavior in Campanula americana. Oecologia $102,174-9$

Kirkpatrick H. E. (1998). Factors affecting the success of California poppy (Eschscholzia californica) introduced into western Washington State. Northwest Sci. 72(3), 180-9.

Klingenberg C. P. (2011) MorphoJ: an integrated software package for geometric morphometrics. Mol. Ecol. Resour. 11(2), 353-7.

Klingenberg C. P. \& Marugán-Lobón J. (2013) Evolutionary covariation in geometric morphometric data: analyzing integration, modularity, and allometry in a phylogenetic context. Syst. Biol. 62(4), 591-610. 
Martin N. (2004) Flower size preferences of the honeybee (Apis mellifera) foraging on Mimulus guttatus (Scrophulariaceae). Evol. Ecol. Res. 6, 777-82.

Mitteroecker P. \& Gunz P. (2009) Advances in geometric morphometrics. Evol. Biol. 36(2), 235-47.

Monteiro L. R. (1999) Multivariate regression models and geometric morphometrics: the search for causal factors in the analysis of shape. Syst. Biol. 48(1), 192-9.

Muñoz A. A., Celedon-Neghme C., Cavieres L. A. \& Arroyo M. T. K. (2005) Bottom-up effects of nutrient availability on flower production, pollinator visitation, and seed output in a high-Andean shrub. Oecologia 143, 126-35.

Nilsson L. A. (1988) The evolution of flowers with deep corolla tubes. Nature 334(6178), 147-9.

Njoku E. (1957) The effect of mineral nutrition and temperature on leaf shape in Ipomoea caerulea. New Phytol. 56(2), 154-71.

Ohara M. \& Higashi S. (1994) Effects of inflorescence size on visits from pollinators and seed set of Corydalis ambigua (Papaveraceae). Oecologia 98(1), 25-30.

Peinemann N. (1998). En: Conceptos de Edafología y Nutrición Mineral. Edi UNS, Bahía Blanca, Argentina. pp. 4-40.

Rohlf F. J. \& Marcus L. F. (1993) A revolution morphometrics. Trends Ecol. Evol. 8(4), 129-32.

Rosas-Guerrero V., Aguilar R., Martén-Rodríguez S. et al. (2014) A quantitative review of pollination syndromes: do floral traits predict effective pollinators? Ecol. Lett. 17(3), 388-400.

da S L Sternberg L., Pinzon M. C., Moreira M. Z., Moutinho P., Rojas E. I. \& Herre E. A. (2007) Plants use macronutrients accumulated in leaf-cutting ant nests. Proc. R. Soc. B. 274(1608), 315-21.
Schiestl F. P. \& Johnson S. D. (2013) Pollinator-mediated evolution of floral signals. Trends Ecol. Evol. 28(5), 307-15.

Tadey M. (2012) Reproductive biology of Monttea aphylla (Scrophulariaceae). Aust. F. Bot. 59(8), 713-8.

Tadey M. \& Aizen M. A. (2001) Why do flowers of a hummingbird-pollinated mistletoe face down? Funct. Ecol. 15(6), 782-90.

Tadey M. \& Farii-Brener A. G. (2007) Indirect effects of exotic grazers: livestock decreases the nutrient content of refuse dumps of leaf-cutting ants through vegetation impoverishment. F. Appl. Ecol. 44(6), 1209-18.

Tibbett M. (2000) Forum. Funct. Ecol. 14(3), 397-9.

Voroney R. P. \& Heck R. J. (2007) The soil habitat. In: Soil Microbiology, Ecology, and Biochemistry, 4th edn(ed E. A. Paul) pp. 25-49. Elsevier Academic Press, Amsterdam.

Zelditch M. L., Swiderski D. L., Sheets H. D. \& Fink W. L. (2004) Landmarks. Geometric Morphometrics for Biologists: A Primer pp. 23-50. Elsevier Academic Press, New York and London.

\section{SUPPORTING INFORMATION}

Additional Supporting Information may be found in the online version of this article at the publisher's web-site:

Appendix S1. Supporting Information. 